\title{
A UNIVERSIDADE ESTADUAL DE CAMPINAS COMEMORA 50 ANOS DE HISTÓRIA
}

José Tadeu Jorge ${ }^{1}$

\begin{abstract}
A comemoração do Jubileu de Ouro da UNICAMP teve início no dia 05 de outubro de 2015 e proporcionou a realização de vários eventos e atividades, até o dia 05 de outubro de 2016, quando a Universidade completa seus 50 anos. Esse extenso calendário cumpre o importante papel de tornar visíveis as grandes contribuições dessa jovem Universidade que completa cinco décadas de história e que tem oferecido inequívocas contribuições à Educação Superior, tanto no ensino de graduação e de pósgraduação, quanto na produção do conhecimento em todas as áreas, além de sedimentar fortes relações com a sociedade.

A Universidade Estadual de Campinas ${ }^{2}$ foi legalmente criada como entidade autárquica em 1962. Contudo, a implantação efetiva somente foi realizada após a publicação do Decreto $n^{\circ} 45.220$, que criou uma Comissão Organizadora ${ }^{3}$, que teve como objetivo estudar e planejar a gradativa formação das unidades da Universidade. A UNICAMP foi oficialmente fundada no dia 5 de outubro de 1966, data de lançamento de sua pedra fundamental.
\end{abstract}

\footnotetext{
${ }^{1}$ Reitor da Universidade Estadual de Campinas, no período 2013-2017. Professor Titular da Faculdade de Engenharia Agrícola (FEAGRI).

${ }^{2}$ LEI n ${ }^{\circ}$ 7655, de 28 de dezembro de 1962 que dispôs sobre a criação da UNICAMP como entidade autárquica.

${ }^{3}$ São Paulo. Decreto n ${ }^{\circ} 45.220$ de 1965, cf. JORNAL DA UNICAMP, Cronologia: Raízes da Unicamp remontam anos 40, ano X, n. 115, p. 8 .

Serv. Soc. \& Saúde, Campinas, SP v.15, n. 1 (21), p. 11-14, jan./jun. 2016 ISSN 1676-6806
} 
A UNICAMP é uma entidade autárquica estadual de regime especial ${ }^{4}$, com autonomia didático-científica, administrativa, financeira e disciplinar. É uma universidade pública e gratuita, que tem um forte compromisso com a excelência na formação e na produção científica. Atualmente, realiza suas atividades em Campinas, Limeira e Piracicaba, produzindo impactos positivos em toda a região, além de contribuir para o desenvolvimento do Estado de São Paulo e do país.

Exemplo inequívoco desta ação é demonstrado, por exemplo, no compromisso com a formação de recursos humanos qualificados e preparados para o exercício profissional em seus 66 cursos de graduação. Para o ano 2017 a UNICAMP está oferecendo 3330 vagas, distribuídas nas Áreas de Artes, Ciências Biológicas e Saúde, Exatas, Humanas e Tecnológicas ${ }^{5}$. Importante destacar que destas vagas, 1140 vagas são ofertadas no período noturno.

No que tange à Pós-graduação a UNICAMP oferece anualmente 153 cursos, sendo 75 deles em nível de Mestrado, 70 em nível de Doutorado e 8 especializações. É a universidade brasileira detentora dos melhores conceitos de avaliação da CAPES (Coordenadoria de Aperfeiçoamento de Pessoal de Nível Superior), do MEC.

As Relações com a Sociedade consolidam o papel relevante da Universidade à medida que permitem levar à população as múltiplas contribuições da geração do conhecimento novo, através de sua produção cultural, do licenciamento de patentes e da participação na formulação de políticas públicas A Extensão oferece anualmente cerca de 1333 cursos por ano, para um público aproximado de 7800 alunos.

A Área da Saúde é outro importante polo de atuação da UNICAMP que marca de modo inequívoco seu vínculo com a sociedade, com a região e com a defesa da política pública de saúde e a defesa da vida. Consolida-se mediante o cumprimento de seu papel na formação, na produção do cuidado à população usuária de Campinas, região e de outros estados da federação e na produção do conhecimento e na inovação científica e tecnológica.

A dedicação da UNICAMP à produção e a difusão do conhecimento através de pesquisas, teses, dissertações, artigos, livros, eventos municipais, regionais, estaduais,

\footnotetext{
${ }^{4}$ Lei Federal $n^{\circ}$ 5540, de 28 de novembro de 1968, especificamente, os artigos 3 e 4.

${ }^{5}$ Para um aprofundamento da temática convido o leitor a consultar http://www.comvest.unicamp.br/cursos/cursos.htmlcf.

Serv. Soc. \& Saúde, Campinas, SP v. 15, n. 1 (21), p. 11-14, jan./jun. 2016 ISSN 1676-6806
} 
nacionais e internacionais tem permitido consolidar seu papel precípuo de contribuir para que a sociedade e a comunidade científica tenham acesso ao conhecimento nos diversos campos de conhecimento aos quais se dedica. Dessa forma, tem sido possível contribuir para o fortalecimento de Campinas e região, bem como do Estado de São Paulo, do Brasil e da comunidade científica nacional e internacional. A ênfase do seu papel tem se dado tanto na formação de jovens alunos que ingressam nas diferentes áreas oferecidas pela Universidade, quanto na consolidação de sólida formação de cientistas, pesquisadores e de profissionais nas áreas de Ciência, Arte, Tecnologia e Inovação através das quais a Universidade tem participado ativamente do cenário da produção, da socialização e da formação de pesquisadores e profissionais no país e no exterior.

A decisão de dedicar um ano inteiro à celebração das raízes, da história e da memória da UNICAMP, contribuiu para que toda comunidade pudesse realizar uma análise crítica, consistente e fundamentada sobre o seu passado, sua inserção no presente e refletir a respeito dos desafios que o futuro nos reserva. Cabe a cada um e a todos nós, a tarefa de continuar a construir e fortalecer uma instituição comprometida com a formação dos nossos jovens e com a produção do conhecimento. Sempre fiel ao espírito da ética e do bem público, contribuir para o avanço da ciência e da qualidade de vida das pessoas, viabilizando o bem estar e a justiça social.

\section{REFERÊNCIAS}

BRASIL. Lei Federal $\mathbf{n}^{\mathbf{0}}$ 5540, de 28 de novembro de 1968, fixa normas de organização e funcionamento do ensino superior e sua articulação com a escola média, e dá outras providências.

JORNAL DA UNICAMP. 30 anos: breve passado, longo futuro. Campinas: Universidade Estadual de Campinas, ano X, N. ${ }^{\circ}$ 115, out. 1996.

SÃO PAULO (Estado). Assembleia Legislativa. Decreto $\mathbf{n}^{\mathbf{0}} \mathbf{4 5 . 2 2 0}$ de 1965, Dispõe sobre a criação da Organização da Universidade de Campinas e da outras providências. Publicado na Diretoria Geral da Secretaria de Estado dos Negócios do Governo, em 9 de setembro de 1965. 
Serv. Soc. \& Saúde, Campinas, SP v. 15, n. 1 (21), p. 11-14, jan.jjun. 2016 ISSN 1676-6806 